\title{
Iron and folic acid: natural, enriched, fortified, and supplements. Analysis of food sources in the Autonomous City of Buenos Aires
}

\author{
María E. Zapata, B.S. and Magister ${ }^{a}$, Alicia Rovirosa, Biochemist, ${ }^{a}$ and \\ Esteban Carmuega, M.D. ${ }^{a}$
}

\begin{abstract}
Introduction. Fortification and supplementation are two strategies for micronutrient deficiency prevention. The objective of this study was to describe the source of iron and folic acid intake throughout the life cycle in the population of the Autonomous City of Buenos Aires.

Population and methods. Analysis of the information collected in the First Survey on Nutritional Food Intake of the Autonomous City of Buenos Aires (2011), which had a probability cluster sampling design. Consumption was assessed by means of a 24-hour recall. Iron and folic acid intake was estimated and categorized into natural content, enriched wheat flour, milk from the Maternal and Child Plan, fortified foods, and supplements.

Results. Out of the 5369 studied individuals, practically all got iron and folic acid from natural contents (58\% and $29 \%$ of intake, respectively). More than $90 \%$ consumed enriched wheat flour, which provided $28 \%$ of iron and $54 \%$ of folic acid. Fortified food consumption and intake varied greatly. Milkintake from the Maternal and Child Plan was small, even in specific groups. Intake from supplements was low, except in children $<2$ years old ( $30 \%$ consumed iron supplements, which accounted for $38 \%$ of iron).

Conclusion. In addition to natural intake from foods, enriched wheat flour accounted for a major source of folic acid and iron in this population; intake from fortified foods and supplements varied by age group.
\end{abstract}

a. Child Nutrition Study Center Dr. Alejandro O'Donnell (Centro de Estudios sobre Nutrición Infantil Dr. Alejandro O'Donnell), Autonomous City of Buenos Aires, Argentina.

E-mail address:

María Elisa Zapata, B.S. and Magister:

mezapata@cesni.org.ar

Funding:

None.

Conflict of interest:

None.

Received: 2-22-2019

Accepted: 10-21-2019

\section{INTRODUCTION}

Nutrients may be obtained from food natural content, nutrients added to certain foods, ${ }^{1}$ and supplements. Nutrient addition may be mandatory when there is an insufficient intake in the population with negative consequences for public health (food enrichment) or may be done through voluntary fortification, promoted by the food industry, ${ }^{2}$ to meet the specific nutritional requirements of a healthy population and to add value to sales.

In our country, the Argentine Food Code regulates which foods may be fortified and the fortification levels. ${ }^{3}$ Fortification and enrichment are some of the main approaches to improve vitamin and mineral consumption at a population level due to their relatively low cost and proven benefits, and are considered one of the most costeffective public health interventions in populations with micronutrient deficiencies. ${ }^{2}$

Argentina has implemented three food enrichment strategies. In 1967, Law no. 17259 established the addition of iodine to salt for human and animal use. Since 2001, Law no. 25459 stipulated the mandatory addition of iron, zinc, and vitamin $\mathrm{C}$ to whole milk powder distributed through food programs to pregnant and breastfeeding women and children $<2$ years old. In 2002, for the purpose of preventing anemia and neural tube defects, Law no. 25630 established wheat flour enrichment with iron and folic acid, and the restoration of thiamin, riboflavin, and niacin lost during wheat milling, a common practice in many countries in the region and worldwide. ${ }^{4}$ Prophylactic supplementation is recommended in risk groups. ${ }^{5,6}$ 
Iron deficiency and anemia are universal public health problems due to their consequences on individual health and on social and / or financial aspects that affect all countries to different extents. Anemia affects people of all ages, but it predominates in young children, women of childbearing potential, and pregnant women. ${ }^{6}$ As per the data from the National Survey on Nutrition and Health of 2005, in Argentina, $16 \%$ of children $<5$ years, $35 \%$ of children aged 6-24 months, $20 \%$ of women of childbearing potential, and $30 \%$ of pregnant women had anemia. ${ }^{7}$ The relation between neural tube defects and folic acid has been described in several clinical and experimental trials. In Argentina, wheat flour enrichment has been associated with adequate serum folate levels and folate intake in women. ${ }^{8}$

Available information on the source of micronutrients consumed in our country is limited. The objective of this study was to describe iron and folic acid intake based on their source in each stage of the life cycle in the population of the Autonomous City of Buenos Aires (CABA).

\section{POPULATION AND METHODS}

This was a descriptive, cross-sectional study. The information collected from the First Survey on Nutritional Food Intake of the City of Buenos Aires (EAN-CABA), ${ }^{9}$ conducted between May and November 2011 with a probability cluster sampling design of individuals in different stages of their life cycle, from children aged 7 months to 12 years, adolescents, mothers of infants $<6$ months old, women of childbearing potential to adults $>60$ years. The information about food and beverage consumption was collected using the 24-hour recall interview method by nutritionists trained on this technique. The following data were collected and recorded: the time food was consumed and the amount and type of food or beverage consumed, specifying the trademark in the case of industrialized products. For children $<13$ years, information was provided by their mothers or caregivers. Information about vitamin and/or mineral supplement consumption was obtained in relation to the previous day. The supplement trademark, dosage, and time of consumption were recorded.

Iron and folic acid content in foods and beverages was established based on nutrient composition tables from Argenfoods, ${ }^{10}$ the Food Analysis and Registration System software, ${ }^{11}$ (Sistema de Análisis y Registro de Alimentos, SARA) the United States Department of Agriculture (USDA) database ${ }^{12}$ and the information provided in the nutrition facts label of fortified foods. Iron and folic acid content from supplements was established based on the information provided by each pharmaceutical company.

Based on the source of iron and folic acid, the following categories were established: 1 . Natural content (foods or beverages without added iron or folic acid); 2. Wheat flour (refined and enriched wheat flour, as per Law no. 25630, and its byproducts, such as bread and cookies); 3. Milk provided by the Maternal and Child Plan (MCP), enriched with iron, zinc, and vitamin $C$; 4 . Fortified foods (foods and beverages fortified with iron and/ or folic acid); 5 . Iron or folic acid supplements.

The statistical analysis was done considering the weighted sample, a statistical technique that allows to correct for sample imbalances and obtain data with better population representativeness. Measures of position, dispersion, and percentage were estimated.

\section{Ethical considerations}

All aspects related to the development of this project have been conducted in accordance with valid national and international standards. An informed consent was signed by participating adults and caregivers of children and adolescents.

\section{RESULTS}

A total of 5369 individuals were assessed. Table 1 shows the main characteristics of each studied group. In relation to iron, all studied individuals consumed foods naturally containing iron, and more than $90 \%$ of those $>2$ years consumed enriched wheat flour or processed foods (Table 2). Voluntarily fortified foods varied greatly; 7 out of 10 children aged 7-23 months got iron from these, basically, infant formula and foods, as well as 1 out of 10 adults. The consumption of milk from the MCP was very low, whereas iron supplements were used by one third of children $<2$ years old and approximately $5 \%$ of older adults and mothers of infants $<6$ months old.

Two-thirds of total iron was obtained from food's natural content, while one third came from enriched wheat flour. The lowest values were observed in children aged 7-23 months and 2-4 years (Table 2 and Figure 1). On their side, fortified foods provided, on average, $7 \%$ in the total population, whereas milk from the MCP, $1 \%$ in children $<4$ years old and mothers of infants 
$<6$ months old. Total iron intake from fortified foods was consistent with a greater or lower consumption throughout the life cycle; in children aged 7-23 months, it accounted for one third of the daily intake; in children aged 2-4 years, one fourth; and in adults $>60$ years, barely $2 \%$ (Table 2 and Figure 1).
In more than $99 \%$ of individuals, folate consumption came from natural food content, while voluntarily fortified foods provided higher levels than those observed for iron. Almost half of the population got folates from fortified foods, but its frequency decreased throughout the life cycle. In children $<2$ years old, 7 out

TABLE 1. Sample characteristics $(n=5369)$

\begin{tabular}{|c|c|c|c|c|c|c|c|}
\hline & $\begin{array}{c}\text { 7-23 } \\
\text { months old }\end{array}$ & $\begin{array}{c}\text { Children } \\
2-4 \\
\text { years old }\end{array}$ & $\begin{array}{c}5-12 \\
\text { years old } \\
\end{array}$ & $\begin{array}{c}\text { Adolescents } \\
13-18 \\
\text { years old } \\
\end{array}$ & $\begin{array}{c}\text { Mothers of infants } \\
<6 \\
\text { months old }\end{array}$ & $\begin{array}{c}\text { Women } \\
19-49 \\
\text { years old } \\
\end{array}$ & $\begin{array}{c}\text { Adults } \\
\quad>60 \\
\text { years old }\end{array}$ \\
\hline Sample (n) & 636 & 765 & 1067 & 920 & 555 & 854 & 572 \\
\hline Weighted sample (N) & 62881 & 129369 & 311877 & 212202 & 26786 & 688508 & 629207 \\
\hline Age (years)* & $1.1 \pm 0,4$ & $2.8 \pm 0.8$ & $8.4 \pm 2.2$ & $15.2 \pm 1.7$ & $29.9 \pm 6.6$ & $33.2 \pm 8.4$ & $71.5 \pm 8.0$ \\
\hline Female $(\%)$ & 48.9 & 48.7 & 49.2 & 49.9 & 100 & 100 & 63.1 \\
\hline
\end{tabular}

Note: * mean \pm standard deviation.

TABLE 2. Iron consumption by source and stage of life cycle (\% of consumers and $m g / d)$

\begin{tabular}{|c|c|c|c|c|c|c|c|c|c|c|c|c|c|c|c|}
\hline & \multicolumn{3}{|c|}{ Natural } & \multicolumn{3}{|c|}{ Wheat flour } & \multicolumn{3}{|c|}{ Milk provided by the MC } & \multicolumn{3}{|c|}{ P Fortified food } & \multicolumn{3}{|c|}{ Supplements } \\
\hline & $\%$ & Mean & SD & $\%$ & Mean & SD & $\%$ & Mean & SD & $\%$ & Mean & SD & $\%$ & Mean & SD \\
\hline Total & 99.9 & 6.6 & 3.8 & 92.4 & 3.2 & 2.6 & 0.5 & 0.0 & 0.4 & 36.7 & 0.8 & 2.3 & 5.5 & 0.8 & 8.3 \\
\hline \multicolumn{16}{|l|}{ Children } \\
\hline $7-23$ months old & 99.4 & 3.0 & 2.1 & 72.5 & 0.8 & 1.0 & 1.4 & 0.1 & 1.5 & 69.5 & 3.9 & 4.2 & 30.2 & 4.8 & 8.7 \\
\hline 2-4 years old & 100.0 & 4.5 & 2.7 & 95.2 & 2.2 & 1.8 & 1.0 & 0.1 & 0.8 & 54.4 & 2.1 & 3.3 & 0.8 & 0.0 & 0.2 \\
\hline $5-12$ years old & 99.9 & 5.9 & 3.1 & 96.4 & 3.5 & 2.6 & 0.1 & 0.0 & 0.1 & 45.9 & 1.4 & 2.7 & 0.4 & 0.2 & 3.2 \\
\hline \multicolumn{16}{|l|}{ Adolescents } \\
\hline $13-18$ years old & 99.9 & 7.2 & 4.2 & 95.2 & 4.7 & 3.6 & 0.1 & 0.0 & 0.4 & 34.0 & 1.2 & 3.0 & 1.4 & 0.1 & 1.6 \\
\hline \multicolumn{16}{|l|}{ Mothers of infants } \\
\hline$<6$ months old & 100.0 & 7.3 & 4.2 & 94.4 & 3.8 & 2.8 & 1.3 & 0.1 & 1.0 & 22.2 & 0.8 & 2.2 & 5.0 & 2.1 & 11.8 \\
\hline Women $19-49$ years old & 100.0 & 6.9 & 3.6 & 92.4 & 3.1 & 2.5 & 0.0 & 0.0 & 0.0 & 16.2 & 0.5 & 1.7 & 2.9 & 1.2 & 12.5 \\
\hline Adults $>60$ years old & 100.0 & 7.3 & 4.2 & 96.7 & 3.2 & 2.2 & 0.0 & 0.0 & 0.0 & 9.6 & 0.2 & 0.9 & 5.1 & 0.7 & 5.5 \\
\hline
\end{tabular}

SD: standard deviation; MCP: Maternal and Child Plan.

FIGURE 1. Iron and folic acid intake by source and stage of life cycle $(\%)$

Iron

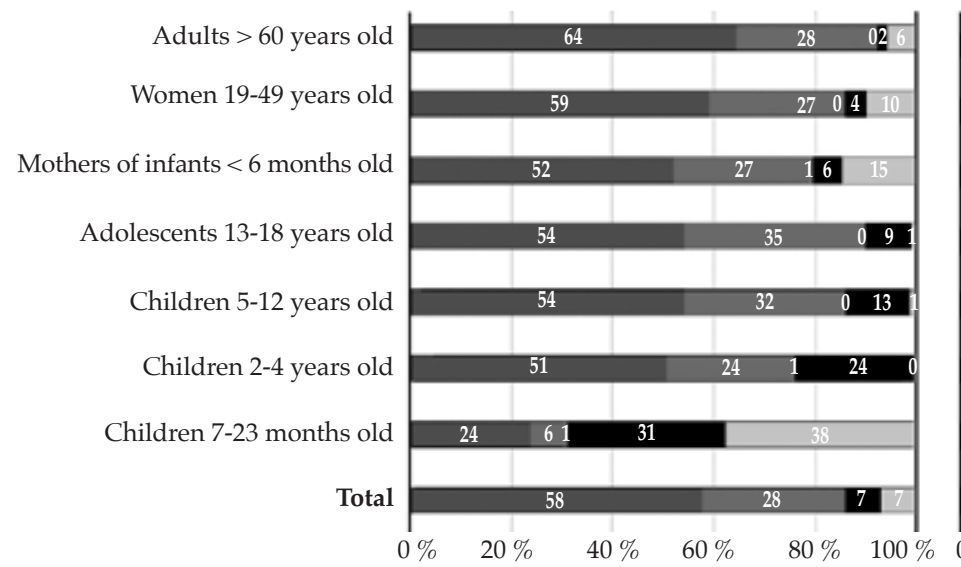

Folate

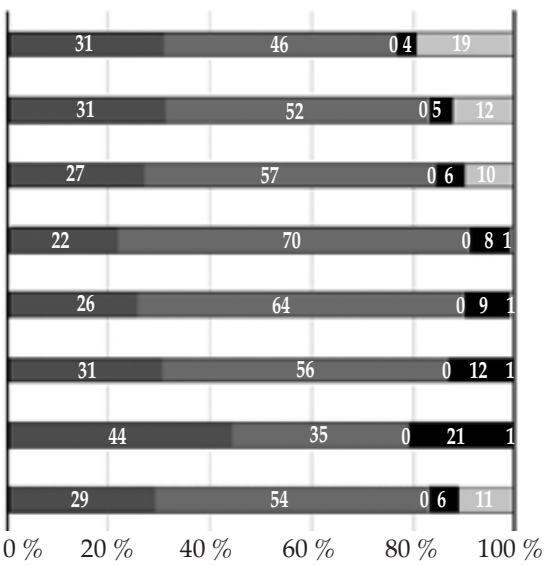

Food (natural content)

Wheat flour (enriched)

Milk provided by the MCP

Fortified food

MCP: Maternal and Child Plan. 
of 10 included folates in their diet, while this was observed in 3 out of 10 older adults. Folate supplement consumption predominated in adult women and older adults and, to a lesser extent, in children and adolescents (Table 3).

Enriched wheat flour was the main source of dietary folate in the studied population. It provided more than half of folate intake, followed by natural food content and voluntarily fortified foods. Wheat flour intake ranged from $35 \%$ to $70 \%$ in children aged 7-23 months and adolescents, respectively. The lowest level of folic acid intake from natural sources was found in adolescents (22\%), and the highest, in children aged 7-23 months (44\%). Intake from voluntarily fortified foods decreased as the population's age increased: in children aged 7-23 months, it accounted for $21 \%$; in children aged 2-4 years, $12 \%$; and in the rest of the groups, less than $10 \%$. Supplements provided $19 \%$ of total folic acid consumed by older adults and more than $10 \%$ of that consumed by mothers and women of childbearing potential, whereas intake from supplements was minimal in the other stages of the life cycle due to a low supplement use (Table 3 and Figure 1).

\section{DISCUSSION}

Micronutrient deficiency is a topic of growing interest $\mathrm{t}^{13}$ because it substantially contributes to the worldwide burden of morbidity and also because it is a public health problem that affects both developing and developed countries, especially vulnerable populations. ${ }^{4} \mathrm{~A}$ balanced diet that contains an adequate quantity of nutrients is the best way to prevent any deficiency but, to this end, it is necessary to provide universal access to adequate foods and appropriate eating habits.
For this reason, strategies have been implemented in order to prevent nutrient deficiencies that entail public health problems, including iodine, vitamin A, iron, and folic acid, among others. Food fortification, both mandatory (enrichment) and voluntary (fortification), either mass or targeted, is considered a cost-effective public health intervention for the management of micronutrient deficiencies and offers the double benefit of providing nutrients to large segments of the population without the need to make radical changes in food consumption patterns. Specific supplementation in risk or vulnerable groups improves nutritional status even more quickly. ${ }^{4}$ There are no local data available about the source of iron and folic acid intake.

Our results show the important contribution of enriched and fortified foods to iron and folic acid intake, especially, wheat flour enriched with folic acid, which doubles the natural food content, and iron fortified infant food and formulas, which largely contribute to iron intake in children. Supplements account for a significant intake in specific groups, like the use of iron in children $<2$ years, which has been established in guidelines. ${ }^{6}$

Given the characteristics of the Argentine diet, natural iron from foods, which accounts for more than half of iron consumption, comes mostly from meat, so it is considered to have a greater bioavailability,,$^{14}$ compared to that from other foods naturally containing iron, like vegetables and legumes, and to that obtained from fortification or enrichment. Wheat flour is enriched with ferrous sulfate, which has demonstrated an adequate bioavailability. ${ }^{4}$

Enrichment of wheat flour with iron is regulated in 84 countries, and with folic acid, in

TABLE 3. Folic acid consumption by source and stage of life cycle (\% of consumers and $m g / d)$

\begin{tabular}{|c|c|c|c|c|c|c|c|c|c|c|c|c|}
\hline & \multicolumn{3}{|c|}{ Natural } & \multicolumn{3}{|c|}{ Wheat flour } & \multicolumn{3}{|c|}{ Fortified food } & \multicolumn{3}{|c|}{ Supplements } \\
\hline & $\%$ & Mean & SD & $\%$ & Mean & SD & $\%$ & Mean & SD & $\%$ & Mean & SD \\
\hline Total & 99.8 & 130 & 115 & 92.4 & 239 & 234 & 46.2 & 26 & 51 & 1.9 & 49 & 612 \\
\hline \multicolumn{13}{|l|}{ Children } \\
\hline 7-23 months old & 99.2 & 79 & 60 & 72.5 & 62 & 89 & 70.9 & 37 & 43 & 0.0 & 0 & 0 \\
\hline 2-4 years old & 99.9 & 87 & 58 & 95.2 & 160 & 164 & 60.3 & 36 & 49 & 0.1 & 1 & 34 \\
\hline 5-12 years old & 99.9 & 105 & 85 & 96.4 & 264 & 239 & 56.4 & 36 & 51 & 0.3 & 4 & 140 \\
\hline Adolescents $13-18$ years old & 99.9 & 114 & 96 & 95.2 & 361 & 324 & 44.2 & 41 & 76 & 1.4 & 3 & 41 \\
\hline Mothers of infants $<6$ months old & 100.0 & 136 & 128 & 94.4 & 288 & 233 & 32.1 & 28 & 60 & 4.9 & 49 & 431 \\
\hline Women 19-49 years old & 99.9 & 135 & 116 & 92.4 & 226 & 222 & 27.3 & 21 & 46 & 3.4 & 53 & 676 \\
\hline Adults $>60$ years old & 99.8 & 157 & 134 & 96.7 & 232 & 206 & 26.6 & 20 & 43 & 5.3 & 97 & 838 \\
\hline
\end{tabular}

SD: standard deviation. 
80 countries. ${ }^{15}$ The evidence has demonstrated that wheat flour enriched with iron reduces iron deficiency anemia ${ }^{16}$ and that enriched with folic acid reduces neural tube defects, folate deficiency, and folate deficiency anemia. ${ }^{17}$ Folic acid intake from wheat flour and products prepared with wheat flour is the main dietary source in all age groups, except in children aged 7-23 months.

These data are consistent with those observed in the analysis of surveys of household expenditures, ${ }_{1}^{14}$ which showed that more than two thirds of apparent folate intake in the Argentine population came from flour, bread, and cookies, that folic acid intake had quadrupled after the implementation of the law, and that flour and its byproducts were the main reason for the increase in intake (from $64 \mu \mathrm{g}$ in 1996-97 to $588 \mu \mathrm{g}$ in 2012-13, per day per adult equivalent). In addition, at a national level, wheat flour enriched with folic acid was associated with adequate folate intake and serum levels in women, and the prevalence of neural tube defects and its associated mortality decreased significantly. ${ }^{8}$

In the case of iron, wheat flour is a major source, but smaller than that of folates. The analysis of the National Survey on Household Expenditures ${ }^{14}$ showed that wheat products provide almost half $(44 \%)$ of dietary iron in the Argentine population, and that there was an increase between the first and the most recent survey as a result of the law, increasing the intake from wheat flour and its byproducts from $3.5 \mathrm{mg}$ in $1996-97$ to $7.0 \mathrm{mg}$ in 2012-13 per day per adult equivalent. Voluntarily fortified foods are becoming a more common option in the market, especially those targeted for specific population groups. As per our results, it has been observed that although they are present in all studied age groups, their presence reduces as age increases.

One of the main strengths of this study is the use of a large, representative sample of each stage of the life cycle in one of the main Argentine cities. In relation to the limitations of the study, it is worth noting that a 24-hour recall interview was used as the source of information about intake. This is a good method to estimate the mean intake, but might underestimate the percentage of consumers and, when only one is done, it is not enough to estimate the risk for an inadequate intake. Another limitation that is worth taking into account is the difficulty to discriminate between the natural content of iron and folic acid in fortified and enriched foods, so the total content was considered as the total for each category, which possibly overestimated the intake in both categories.

Having information about the sources of dietary iron and folic acid throughout the life cycle is very relevant to the assessment of the impact of enrichment policies on the population, the natural intake from food, and the consumption of fortified foods. In order to complement and even extend the scope of this information, it would be useful to assess the risk of an inadequate intake, both insufficient and excessive, the coverage of recommendations, and the nutritional status of these nutrients, especially in population groups at risk. The data of this study have demonstrated that, in addition to natural intake from foods, enriched wheat flour accounts for a major source of folic acid and iron in this population; whereas intake from fortified foods and supplements varies by age group.

\section{REFERENCES}

1. Fulgoni VL 3rd, Keast DR, Bailey RL, Dwyer J. Foods, fortificants, and supplements: Where do Americans get their nutrients? J Nutr. 2011; 141(10):1847-54.

2. World Health Organization. WHO Meeting on estimating appropriate levels of vitamins and minerals for food fortification programmes: The WHO Intake Monitoring, Assessment and Planning Program (IMAPP): meeting report. Geneva: WHO: 2010.

3. Ministerio de Salud de la Nación. Alimentos de régimen o dietéticos. Artículo 1347 - (Res 1542, 12.09.90). In: Código Alimentario Argentino. 2013. [Accessedon: October 22 nd, 2019]. Available at: http: / / www.alimentosargentinos.gob. ar/contenido/marco/CAA/Capitulo_17.htm.

4. Allen L, De Benoist B, Dary O, Hurrell $\mathrm{R}$ (eds.). Guidelines on food fortification with micronutrients. Paris: World Health Organization, Food and Agricultural Organization of the United Nations; 2006.

5. AbeyáGilardon E, Calvo E, Durán P, Longo E, et al. Evaluación del estado nutricional de niñas, niños y embarazadas mediante antropometría. Buenos Aires: Ministerio de Salud de la Nación; 2009.

6. Comité Nacional de Hematología, Oncología y Medicina Transfusional, Comité Nacional de Nutricion. Deficiencia de hierro y anemia ferropenica. Guía para su prevención, diagnostico y tratamiento. Resumen ejecutivo. Arch Argent Pediatr. 2017; 115(4):406-8.

7. Ministerio de Salud de la Nación. Encuesta Nacional de Nutrición y Salud. Documento de resultados. Buenos Aires: MINSAL; 2007.

8. Calvo E, Biglieri A. Impacto de la fortificación con ácido fólico sobreel estado nutricional en mujeres y la prevalencia de defectos del tubo neural. Arch Argent Pediatr. 2008; 106(6):492-8.

9. Gobierno de la Ciudad Autónoma de Buenos Aires. Primera Encuesta Alimentaria Nutricional de la Ciudad de Buenos Aires. Documento de resultados 2011. Buenos Aires; MINSAL; 2013.

10. Argenfoods. Tablas de composición de alimentos. Universidad de Luján; 2016. [Accessed on: October $22^{\text {nd }}$, 2019]. Available at: http: / / www.argenfoods.unlu.edu.ar / Tablas / Tabla.htm. 
11. Ministerio de Salud de la Nación, Dirección Nacional de Salud Materno Infantil. Software SARA. Sistema de Análisis y Registro de Alimentos, Versión 1.2.22 ed. 2007.

12. US Departament of Agriculture, Agricultural Research Service. Food Data Central. [Accessed on: October 22 ${ }^{\text {nd }}$, 2019]. Available at: https: / / fdc.nal.usda.gov/.

13. Mozaffarian D, Rosenberg I, Uauy R. History of modern nutrition science-implications for current research, dietary guidelines, and food policy. BMJ. 2018; 361:k2392.

14. Zapata ME, Rovirosa A, Carmuega E. La mesa argentina en las últimas dos décadas. Cambios en el patrón de consumo de alimentos y nutrientes (1996-2013). Buenos Aires: CESNI; 2016.

15. Pachón H. History of Food Fortification. New Delhi: Food Fortification iniciative; 2016.

16. Pachón H, Spohrer R, Mei Z, Serdula MK. Evidence of the effectiveness of flour fortification programs on iron status and anemia: a systematic review. Nutr Rev. 2015; 73(11):780-95.

17. Arth A, Kancherla V, Pachón H, Zimmerman S, et al. A 2015 global update on folic acid-preventable spina bifida and anencephaly. Birth Defects Res A Clin Mol Teratol. 2016; 106(7):520-9. 